\title{
EMPODERAMIENTO FEMENINO Y COMPETITIVIDAD: caso restaurante Tierra y Cielo, en San Cristóbal de Las Casas, Chiapas, México
}

\author{
Carlos Jesús González-Macías \\ cgonzalez@uacj.mx \\ Tomás Jesús Cuevas-Contreras \\ tcuevas@uacj.mx \\ IsABEL ZizALDRA-HERnÁNDEZ \\ izizaldr@uacj.mx \\ Universidad Autónoma de Ciudad Juárez
}

\begin{abstract}
El presente estudio de caso es un análisis de las acciones empresariales de empoderamiento femenino en la propietaria del restaurante Tierra y Cielo, en San Cristóbal de Las Casas. El liderazgo femenino marca su gestión en el establecimiento, al competir a partir de elementos sustentables que contribuyen en lo local-regional. El estudio gira en torno a la perspectiva de género, la competitividad y el desarrollo femenil en el ámbito de la gastronomía. La aproximación al tema es cualitativa, con base en el modelo tridimensional de Rowlands, mediante una entrevista a profundidad a la visionaria culinaria de Chiapas, así como la observación no participante y el sondeo a empleados de la empresa. En cuanto al análisis de los resultados, se realiza mediante el contraste de la tríada dimensional y los rasgos que potencian el empoderamiento femenino, los cuales definen redes semánticas, que puntualizan la evolución del empoderamiento y liderazgo en cuestión.
\end{abstract}

Palabras clave: Empoderamiento, competitividad, restaurante sustentable, estudio de caso, enfoque de género.

\section{FEMININE EMPOWERMENT AND COMPETITIVENESS: THE CASE of the Tierra y Cielo restaurant in San Cristóbal de las Casas, Chiapas, México}

This case study analyzes female empowerment through the entrepreneurial actions implemented by the owner of the Tierra y Cielo restaurant, in San Cristóbal de las Casas. Feminine leadership in this establishment is set by the local and regional competition performed with sustainable elements. The study revolves around gender perspective, competitiveness, and women's development in the field of gastronomy. There is a qualitative approximation to this topic based on Rowlands' three-dimensional model, through an in-depth interview with Chiapas' culinary visionary, as well as a non-participant observation, and questionnaires to the staff. The analysis of results is done by contrasting the dimensional triad and the traits enhancing female empowerment, which define semantic networks and identify the evolution of empowerment and leadership in question.

Keywords: Empowerment; competitiveness; sustainable restaurant; case study; gender focus.

Fecha de recepción: 26 de marzo de 2018. Fecha de aceptación: 11 de junio de 2018

CÓMO CITAR: González-Macías, C., Cuevas-Contreras, T. y Zizaldra-Hernández, I. (2018). Empoderamiento femenino y competitividad: caso restaurante Tierra y Cielo, en San Cristóbal de Las Casas, Chiapas, México. Dimensiones Turísticas, 2(3), 48-74. https://doi. org/10.47557/CLNR7199 


\section{Introducción}

\section{Antecedentes}

La actividad turística se comporta como un sistema complejo donde las propiedades del conjunto son diferentes de la mera suma de las partes, y se caracteriza por su sensibilidad ante fenómenos ajenos a los estrictamente económicos, la heterogeneidad de los servicios que abarca y la intensa interdependencia y amplitud de los sectores implicados directa o indirectamente. "Ya que el turismo no figura como una actividad productiva específica en la Clasificación Nacional de Actividades Económicas, este se encuentra desarrollándose, por tanto, a través de diversos sectores económicos" (Cobo Quesada, Hervé y Aparicio Sánchez, 2009, pp. 429-430), como el de los restaurantes.

Dentro de la actividad turística, el giro de restaurantes es el que más aperturas, traspasos y quiebras genera año con año. En la actualidad, las condiciones que preponderan en el mercado definen un ambiente sumamente competitivo para las empresas, en el cual una de las principales exigencias en la actividad empresarial es profesionalizarse a fin de ofrecer a los clientes, cada vez más conocedores y exigentes, un mejor servicio, calidad y, sobre todo, innovación (Durón, 2012, p. 15).

La industria restaurantera en México capta, en promedio, 28 \% del gasto efectuado por cada turista y visitante, nacional y extranjero, y aporta $3 \%$ al producto interno bruto nacional. Existen en territorio nacional 220000 establecimientos de alimentos y bebidas, de los cuales $4 \%$ pertenece al tipo de franquicia, nacional y transnacional, y el restante $96 \%$ lo conforma el segmento de restaurantes tradicionales (Cámara Nacional de la Industria de Restaurantes y Alimentos Condimentados [Canirac], 2014). "Aunque este segmento genera el $45 \%$ de las ventas totales de la actividad y el $56 \%$ de los empleos, es el más sensible y vulnerable a todos los problemas y movimientos de la economía nacional" (Durón, 2012, p. 5). Como indican Dressler y Varela (2016), todos los restaurantes influyen de manera importante sobre el mercado interno, así como también en el crecimiento económico de México; por ello, los índices de productividad y su impacto en la competitividad del sector toman gran relevancia.

Para lograr el éxito ante los competidores, se requiere desarrollar en los restaurantes habilidades y capacidades de servicio que combinen el sentido común, que muchos de los empresarios poseen, con la colaboración necesaria para alcanzar los resultados deseados al momento de realizar sus actividades; "esta filosofía básica puede resumirse de la siguiente manera: "hacer que las cosas sucedan"” (Franco, 2012, p. 73).

\section{Planteamiento del problema}

Tierra y Cielo, ubicado en la ciudad de San Cristóbal de Las Casas, Chiapas, en México, innova al ser el primer restaurante en el estado en obtener diversos premios, reconocimientos y distinciones de prestigio nacional e internacional. Esto gracias a las acciones realizadas por su propietaria y líder, que ha considerado apoyos para el reforzamiento de 
sus capacidades individuales en términos productivos dentro de la lógica de costo-beneficio (Román, 2000). Es así como se ha manifestado en el trabajo colectivo, al integrar específicamente a los pequeños productores de la comunidad como sus únicos proveedores, y a los integrantes de las comunidades indígenas como sus empleados. Este es su principal eje de acción, de manera que ha establecido una forma de trabajo significativa en el plano local. De tal suerte, resulta necesario el análisis de cómo se han llevado a cabo las actividades en el restaurante, pues en él se destacan elementos del ámbito sustentable, de colaboración y soporte a otras entidades.

Es cierto que esta clase de acciones no son frecuentes cuando se visualiza una operación de venta de alimentos y bebidas, pues resulta más común una gestión tipo occidental (proveedores institucionales, franquicias y cadenas, incorporación de manuales de operación estandarizados, entre otros). De modo que, al considerarse los diferentes actores e interesados en la gastronomía local, estas acciones incorporan un dinamismo inusitado y prácticamente inexistente.

El caso de Tierra y Cielo ofrece una vasta gama de oportunidades de generación de conocimiento para todos aquellos estudiosos del ámbito de la gastronomía con la incorporación de ingredientes locales, así como para el desarrollo de oportunidades para emprendedores con un enfoque diferenciado. Esta nueva forma de la gestión de operaciones en el caso de los restaurantes es significativa, gracias a los rasgos del empoderamiento femenino que se hacen presentes, a diferencia de la visión tradicionalista de dominio masculino, donde la administración de la cocina quedaba en manos homogéneas. Solo hay que recordar a Escoffier y otros más que han dejado su influencia por largo tiempo, desde la cocina francesa hasta la actualidad.

Por otra parte, la gran mayoría de los estudios del fenómeno de la gestión operativa de restaurantes cuenta con un enfoque cuantitativo (costos de operación, relación costo/ beneficio, presupuestos de ventas, etc.), mas no se han realizado estudios que permitan una cualificación de las actividades que se llevan a cabo en el día a día. Estas además influyen en el desarrollo de su actividad, como son estado de ánimo, estilo de liderazgo, percepciones, personalidades, prejuicios, condiciones del entorno, entre otras. De tal forma que esta influencia se encuentra presente en las tres dimensiones de Rowlands (1998) del empoderamiento femenino, identificadas en la propietaria.

Así, se cuestiona, por una parte, ¿cuál es el enfoque entre la competitividad y el empoderamiento que requiere el liderazgo femenino en el ámbito restaurantero?; por otra parte, ¿los procesos y conductas observados por la propietaria condicionan su gestión empresarial? y, además, ¿el liderazgo que ella desempeña es percibido como multifacético?

El objetivo general de la presente investigación dispone analizar las gestiones operativa y empresarial en el restaurante que permiten un nivel de competitividad sustentable a partir del empoderamiento femenino. En tanto, los objetivos específicos son: a) Explorar las acciones que impulsan la competitividad y sustentabilidad en el restaurante; b) Comprender los procesos, conductas y condiciones de la persona frente a las acciones empresariales; y c) Examinar la naturaleza multifacética de las acciones humanas en el liderazgo 


\section{J. González-Macías · T. J. Cuevas-Contreras · I. Zizaldra-Hernández}

femenino. Se destacan tres supuestos: 1. Las acciones de empoderamiento femenino impulsan la competitividad y sustentabilidad; 2. Los procesos y conductas condicionan las acciones empresariales; 3 . El liderazgo femenino es multifacético.

\section{Revisión de literatura}

La revisión se ha enfocado en el empoderamiento femenino, la competitividad y la innovación, y la relación entre ellos. Estas orientaciones permiten el escrutinio como visiones diferenciadas, ya que en el ambiente de la gastronomía ha predominado un punto de vista más masculino. De tal manera, se explora el matiz femíneo.

\subsection{Empoderamiento femenino}

El término empoderamiento femenino se utiliza desde la perspectiva colectiva de desarroIlar un cambio sustancial en la cultura de las sociedades actuales, sobre todo cuando se relaciona a la mujer con el uso del poder (León, 2007). De acuerdo con Erazo, Jiménez y López (2014, p .150):

El concepto sociopolítico de empowerment o empoderamiento se originó en Estados Unidos, durante los años sesenta, en los movimientos de derechos civiles, vinculados a ideologías sociales y políticas que revelan una opresión y reclaman la equidad y responde a las necesidades de generar cambios dentro de las relaciones de poder entre géneros.

El empoderamiento también puede entenderse como todo aquel proceso por el cual todos aquellos que no han tenido la oportunidad de tomar decisiones de vida estratégicas adquieren tal capacidad (Kabeer, 1999, p. 440). Para Montero (2003), el empoderamiento se presenta como ese proceso donde aquellas personas pertenecientes a una comunidad desarrollan de manera conjunta capacidades y recursos, propios y compartidos, para controlar su situación de vida, llevándolo a cabo de manera comprometida, consciente y crítica, transformando su entorno de acuerdo con la satisfacción de sus necesidades y aspiraciones, al mismo tiempo que se transforman a sí mismos.

Ahora bien, se debe incorporar a las mujeres como parte del necesario desarrollo de toda comunidad, fortaleciéndoles y favoreciéndoles el empoderamiento, ya que este concepto comprende no solo el proceso, sino también el resultado en el cual las mujeres obtienen un mayor control sobre los recursos intelectuales y materiales, desafiando con ello a la férrea ideología del patriarcado y la discriminación por género, que limita las oportunidades de las mujeres para tener acceso y desarrollarse en igualdad de condiciones en diversos ámbitos: político, social, económico y cultural, entre otros (Vázquez-Luna, Mortera, Rodríguez-Orozco, Martínez y Velázquez, 2013; Camberos, 2011; Casique, 2010). Si bien el empoderamiento ha sido una tendencia masculina entre el poder y la violencia, ahora en los países desarrollados esta idea sucumbe ante el movimiento feminista orientado a un marco capitalista equilibrado, 
fomentando a través de él la participación activa y formal de las mujeres en la economía (Lino, 2013; Buendía-Martínez y Carrasco, 2013; Matthaei, 2010).

Por lo anterior, el empoderamiento femenino es producto de una evolución personal experimentada por la mujer. Dentro de este nuevo contexto global permeado de influencias de diversos universos culturales, la mujer posee el derecho de empoderarse a sí misma. Ya no le es posible entender el hecho de dar poder a otras personas sin que sea aceptado el hecho de que ella también puede detentar ese poder. La mujer logra, entonces, un verdadero empoderamiento, plenamente reconocido dentro de la estructura social en la cual interactúa y que, por ende, la valora (Sáez, Valor-Segura y Expósito, 2012).

A pesar de que para la mujer ha sido difícil conseguir tal reconocimiento de su derecho de empoderarse, sí se ha podido abrir espacios y darse posibilidades para que este proceso se lleve a cabo; de ahí la importancia de crear conciencia de la discriminación de género y del compromiso de las organizaciones como agentes facilitadores de este (Zapata, Townsend, Rowlands, Alberti y Mercado, 2002).

Ante este entorno existen distintos ejemplos de empoderamiento (Erazo, Jiménez y López, 2014; Zapata et al., 2002) que afirman que la autogestión comunitaria ha sido exitosa a través del aprovechamiento de los recursos de los cuales dispone y desarrolla la mujer, que han marcado la diferencia entre el enfoque masculino. Luego entonces, su intervención social no es solo la antesala del equilibrio que debe de existir en la gestión empresarial.

En el presente estudio de caso se incorpora el concepto de empoderamiento femenino desarrollado por Rowlands (1998), quien distingue entre condición y posición de las personas y establece qué condición se refiere al estado material en el cual se encuentran: su condición económica, su nivel de educación y capacitación, su carga de trabajo, su acceso a la tecnología, y la posición supuesta de la ubicación social y económica de las mujeres respecto a los hombres.

Con base en su planteamiento, Rowlands (1997) define el empoderamiento como todo ese conjunto de procesos psicológicos que cuando se presentan y son desarrollados por la persona o el grupo los capacitan para desenvolverse y actuar dentro de su entorno de una manera en la cual su acceso al poder se incrementa y los posibilita a utilizarlo en varias formas. En este mismo orden de ideas, amplía la definición del concepto al resumir:

el empoderamiento es un conjunto de procesos que pueden ser vistos en las dimensiones individual, colectiva y de las relaciones cercanas, centrado alrededor del núcleo de desarrollo de confianza, la autoestima, el sentido de la capacidad individual o grupal para realizar acciones de cambio y la dignidad [Rowlands, 1996, p. 230].

Por otra parte, plantea que los intereses de las personas no son homogéneos y determina la diferencia entre intereses prácticos y estratégicos. Los primeros corresponden a los que se derivan del hecho de que a las mujeres les son asignados ciertos roles por la división sexual del trabajo y normas hegemónicas de género (por ejemplo, educación, pobreza, entre otros), mientras que los segundos tienen como fin cambiar la subordinación de la mujer (su ubicación social), buscando una sociedad más igualitaria. Rowlands acota 
que para que estos últimos intereses puedan ser abordados "es necesario ver las dinámicas de poder de género" (1998, p. 214).

La autora en cuestión crea un modelo a partir de las dinámicas de poder de género: "poder sobre", que es la habilidad para que una persona o un grupo haga algo en contra de sus deseos, esto es, un poder de suma negativa: para que uno gane, el otro debe perder. El segundo es un "poder para", que es el poder que tienen las personas para estimular las actividades de otros; luego, el "poder con", un poder sumatorio de poderes individuales; y, finalmente, el "poder desde dentro", aquel que reside en cada individuo; estas tres últimas clases las denomina de suma positiva, donde todos los involucrados ganan.

A partir de los argumentos anteriores, se deduce que el empoderamiento femenino puede ser modificado en tres dimensiones: la dimensión personal, que consiste en desarrollar el sentido del ser, la confianza y las capacidades individuales; la dimensión de las relaciones cercanas, relativa a desarrollar la habilidad para negociar e influenciar la naturaleza de las relaciones del ámbito cotidiano; y la dimensión colectiva, donde se trabaja en conjunto con otros para lograr un mayor impacto y cambios significativos.

El empoderamiento femenino, asimismo, debe ser más que la simple apertura al acceso para la toma de decisiones, debe incluir también procesos que permitan a las mujeres tener la capacidad de percibirse a sí mismas como aptas para ocupar los espacios de toma de decisiones y usar esos espacios de manera efectiva. Así, los procesos de autogestión se encauzan y dirigen sus esfuerzos a desarrollar una lucha contra el paternalismo, edificando entonces, sobre las fuerzas ya de por sí existentes en la persona o grupo social, todas sus capacidades para "potenciarlas" y aumentar las fuerzas preexistentes (Erazo et al., 2014).

\subsection{Competitividad e innovación}

La competitividad puede entenderse como todos aquellos resultados provenientes de la creación y desarrollo de innovaciones y procesos tecnológicos de los actores protagonistas que se desenvuelven dentro de un determinado contexto, llámense estos empresas, instituciones u organizaciones, las cuales permanecen ligadas a las actividades de transformación técnica u organizacional (Bianco, 2007). Debido a esto, los encargados de las empresas deben estar siempre a la vanguardia de la información y procedimientos para sobresalir competitivamente en el mercado. Según Manucci (2010, p. 95):

la competitividad es el resultado de un juego de posiciones y movimientos necesarios para mantener el protagonismo (personal, grupal o corporativo) en la dinámica del entorno actual. No tiene que ver con la fuerza, el tamaño o el poder material, sino con la capacidad de interacción para ser percibidos y valorados en el contexto de actores volátiles y reglas del juego variables.

Los aspectos que conforman el conocimiento en las empresas ponen de manifiesto que todos aquellos atributos importantes, tales como la flexibilidad y la capacidad innovadora que se crean y desarrollan dentro de ellas, se visualizan en la actualidad como prioritarios y esenciales para generar competitividad en los mercados (La Rovere y Hasenclever, 
2010). Lo anterior tiene su razón de ser debido a que los negocios familiares conforman el grupo predominante de empresas que contribuyen significativamente a la creación de empleos, a la generación de ingresos y a satisfacer necesidades en ciertos mercados que son poco atractivos para las grandes organizaciones (Hernani y Hamann, 2013).

Dentro de esta conceptualización, destacan las aportaciones de Porter (1990, 2004), quien define la competitividad sobre la base de las ventajas competitivas mediante un "diamante" dinámico, determinado tanto por las condiciones de oferta, demanda, estructura de las propias empresas y su entorno, como por las relaciones con sus proveedores y clientes.

Porter (1985) explica cómo una empresa puede crear y sostener una ventaja competitiva que le dé diferenciación, con la cual buscará que su producto o servicio sea percibido como algo "único" en las distintas dimensiones que son valoradas por los posibles clientes. Afirma que la estrategia de diferenciación le da a la empresa habilidades y recursos necesarios mediante una gran aptitud para la comercialización e ingeniería del producto, además de un instinto creativo e innovador.

La Rovere y Hasenclever (2010) mencionan que el debate sobre la capacidad innovadora de las empresas familiares surge del hecho de que ellas son diferentes al respecto, ya que tal capacidad no es fácilmente adquirida debido al carácter tácito, acumulativo y localizado del conocimiento técnico y científico que se debe generar. Por ello es necesario para la empresa utilizar el proceso de aprendizaje para la toma de decisiones como estrategia fundamental en la adquisición de conocimiento y la construcción de ventajas que la ayuden a ser competitiva en el mediano y largo plazo (Pérez y Cortés, 2007).

El estudio de la competitividad de las empresas familiares ha sido aproximado, según Saldívar González, García Rivera, Valenciana Moreno y Roa Rivera (2012), desde dos enfoques. Primero, desde el externo: el entorno macroeconómico, donde las empresas tienen poca injerencia en la solución de la problemática que enfrentan, dado que no han podido desarrollar una capacidad de reacción competitiva, pues los recursos que poseen son escasos. Segundo, desde el interno: todos los problemas derivados de la propia gestión de las empresas y del sector económico al que pertenecen y en el que compiten. De acuerdo con Millán y Marín (2014), existe una estrecha relación entre la competitividad y las decisiones que se toman, debido al impacto en todos los involucrados y cómo abordan las cuestiones prioritarias para la empresa.

\subsection{Empoderamiento femenino y competitividad}

Al relacionar el empoderamiento femenino de Rowlands (1998) con la competitividad descrita por Porter (1990), se observa que las líneas teóricas de estas variables conciben a la gestión empresarial realizada por una mujer como un activo valioso, pero protegerlo dentro de la empresa se torna complicado. Como en cualquier persona, cuando esta permanece en la empresa el activo también, pero al irse a su casa se lo lleva, reservándoselo para sí misma. 
En la actualidad, cada vez es más común recurrir al concepto de empoderamiento con referencia a la mujer, por ello, el tipo de gestión y el liderazgo relacionados con el fenómeno de estudio se orientan a permitir el acceso de las mujeres a los recursos y a la toma de decisiones, tanto individuales como colectivas, y a conseguir que ellas se perciban a sí mismas capaces y legítimas para ocupar un espacio en la toma de decisiones (Erazo et al., 2014).

Sin embargo, los factores que componen las dimensiones del empoderamiento en el entorno de la empresa, ya sea interno o externo, son, por naturaleza, inciertos. Empero, si estos se tratan de forma concreta como un activo de ella, le proporcionarán certeza, volviéndose un apoyo para tomar riesgos con menor incertidumbre, y ayudándole a enfocar sus habilidades en innovar y permanecer competitiva. De ese modo, tales factores se convierten en activos intangibles y deben ser valorados a la par de los activos materiales de la empresa, ya que le brindan ventajas competitivas importantes.

El empoderamiento de una mujer empresaria, según Hernani y Hamann (2013), se fundamenta en la creación de valor por medio de actividades que promuevan el uso y aprovechamiento de tecnologías disponibles y un enfoque en el desarrollo económico, ambos encaminados a un mejor posicionamiento competitivo. Los acuerdos de cooperación que ella promueva entre los involucrados responden a la importancia general de este tipo de estrategias en el mundo empresarial. La cooperación adquiere incluso mayor relevancia en las empresas, debido a su clara naturaleza sistémica, donde todos los agentes intervienen

y deben unir esfuerzos para lograr un mejor servicio y la satisfacción final del cliente (Cobo Quesada et al., 2009).

\subsection{Contexto de San Cristóbal de Las Casas, Chiapas, México}

La frontera sur de México se encuentra comprendida en un territorio de aproximadamente 965 kilómetros. La apertura comercial México-Centroamérica, en lo que se refiere a su estructura productiva del sector rural de Chiapas, ha tenido efectos de alcance en el mediano y largo plazo que han podido modificar la estructura agrícola. El acercamiento de México al istmo centroamericano ha constituido una posibilidad para el desarrollo de las economías (Villafuerte, 2011).

Las principales ciudades son Tuxtla Gutiérrez, Tapachula de Córdova y Ordóñez, San Cristóbal de Las Casas, Ocosingo, Comitán de Domínguez y Palenque. Cabe puntualizarse que el fenómeno de la pobreza alimentaria en Chiapas se extiende en una amplia franja de municipios rurales cuya población se halla dispersa en el territorio. Tal como lo señala el diagnóstico gubernamental:

La pobreza se encuentra mayormente extendida en las zonas rurales que urbanas, ocho de cada diez chiapanecos en poblaciones rurales se encuentran en pobreza extrema, cuyo gasto en consumo es inferior a la línea de pobreza alimentaria o canasta básica, mientras que en las zonas urbanas la cifra es de cinco pobres por cada diez habitantes [Centro de Estudios para el Desarrollo Municipal y Políticas Públicas, 2014]. 
Aunado al grado de dispersión poblacional presente en la entidad, su accidentada orografía dificulta la adecuada provisión de servicios básicos, como agua, drenaje y electricidad, hecho que sin duda afecta principalmente a las localidades rurales, pero que ocurre de igual manera en las principales poblaciones, como Tuxtla Gutiérrez y San Cristóbal de Las Casas, las cuales muestran bajos grados de marginación, a diferencia del resto de la entidad. Por otra parte, un segmento importante de los habitantes de estas localidades dispersas en el territorio está formado por diferentes grupos étnicos, que históricamente han padecido graves rezagos en educación, salud, alimentación, y viven en situaciones de exclusión social.

Comitán de Domínguez, San Cristóbal de Las Casas, Tapachula y Tuxtla Gutiérrez han funcionado como ejes del desarrollo regional en Chiapas, y desde la década de 1990 han venido experimentando un crecimiento más rápido que el resto de las poblaciones de la entidad, lo cual ha traído consigo problemas asociados con la concentración poblacional urbana: competencia por el espacio, alto índice de especulación del suelo, deterioro ambiental y proliferación de asentamientos irregulares.

Es decir, el crecimiento demográfico de San Cristóbal de Las Casas se disparó durante la década de 1970; su población creció a una tasa media anual de 5.04\% entre 1970 y 1980, se incrementó a 5.7 en el decenio 1980-1990, y su ritmo se aceleró en el periodo 1995-2010, cuando la principal ciudad de los Altos de Chiapas creció a una tasa media anual de $6.22 \%$ (Instituto Nacional de Estadística y Geografía, 2015), hasta llegar a concentrar 166460 habitantes.

Esta tendencia de la urbanización de San Cristóbal se explica en gran medida por el aumento de actividades ligadas a los servicios para el turismo, la expansión de la burocracia gubernamental, y la creación de centros de investigación y de educación superior en los últimos 40 años, según el Instituto de Población y Ciudades Rurales (2013). Asimismo, San Cristóbal de Las Casas exhibe un rango de complejidad urbana mayor que el resto de las ciudades importantes del estado, cuya tendencia de crecimiento es bastante moderada.

De acuerdo con la Canirac (2014): “En materia de empleo el sector de alojamiento temporal y de preparación de alimentos y bebidas (Sector 72) continúa siendo el sector líder en generación de empleo y autoempleo dentro de los servicios no financieros". En este sentido, la Canirac indica que la actividad restaurantera en Chiapas se encuentra representada por 19052 establecimientos, lo que significa $3.7 \%$ del total nacional.

De los restaurantes en San Cristóbal de Las Casas, el dato contemplado es del giro de alimentos, el cual representa un total de 212 establecimientos. Pero para efectos de la orientación del manuscrito, no se tuvieron en cuenta: taquerías y torterías, bares, piano bar, discotecas y salones de baile. En el cuadro 1 se consideran 184 establecimientos.

Tierra y Cielo forma parte del $65 \%$ de los establecimientos ubicados en el centro que cuenta con cocina regional de Chiapas a la carta. Se sitúa en una casona del Centro Histórico de San Cristóbal de Las Casas (véase figura 1), donde: 
CuadRo 1. Distribución de servicios de preparación de alimentos en San Cristóbal de Las Casas

\begin{tabular}{lccl}
\multicolumn{1}{c}{ Establecimientos } & Cantidad & Porcentaje & \multicolumn{1}{c}{ Observaciones } \\
\hline Cafeterías & 31 & 17 & Servicio semipersonalizado \\
Comida internacional & 20 & 11 & Servicio personalizado \\
\hline Comida rápida & 12 & 7 & Autoservicios \\
\hline Fondas y cocinas económicas & 2 & 1 & Servicio semipersonalizado \\
\hline Restaurantes & 119 & 65 & Servicio personalizado \\
\hline Total & 184 & 100 & \\
\hline
\end{tabular}

Fuente: Elaboración propia con base en Trujillo Rincón (2015).

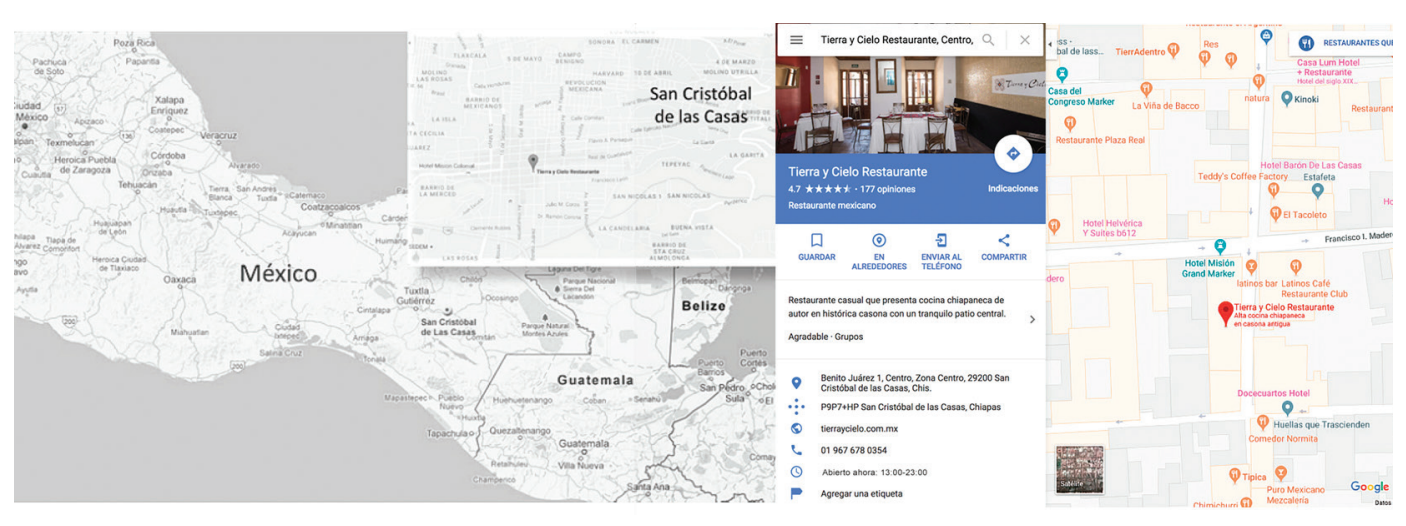

Fuente: Elaboración propia con base en https://www.google.com/maps/ y http://www.vivesancristobal.com/mapas-de-san-cristobal-de-las-casas/

Figura 1. Mapa de ubicación en San Cristóbal: Tierra y Cielo

[se] capitaliza la riqueza cultural, tradiciones y recursos naturales de Chiapas. Fundado en enero de 2007, como parte del proyecto de Tesis de la chef chiapaneca (su propietaria), quien es egresada del Centro de Estudios Superiores de San Ángel, CESSA. La chef busca hacer de la cocina chiapaneca un producto gastronómico turístico, donde se promueven la sustentabilidad y el comercio justo mediante el apoyo a productores, artesanos, colaboradores y proveedores locales. Tierra y Cielo es reconocido como el mejor restaurante del estado de Chiapas. Entre sus galardones destacan el Premio Nacional de Calidad 2015 y el reconocimiento del Conservatorio de la Cultura Gastronómica de México 2017 [www.tierraycielo.com.mx].

El restaurante cuenta con cuatro reconocimientos nacionales (véase cuadro 2), independientemente de que su propietaria cultiva el desarrollo sustentable, al promover la gastronomía local, el consumo responsable, y se esfuerza por fortalecer la economía local 
para transformarla en bienestar comunitario para San Cristóbal de Las Casas. Tierra y Cielo ha sido reconocido como el mejor restaurante de Chiapas por la Guía México Gastronómico 2017, así como en 2016, entre los 120 mejores restaurantes del país. Además del Reconocimiento del Conservatorio de la Cultura Gastronómica de México 2017, en el Foro Mundial de la Gastronomía.

Cuadro 2. Premios y distinciones al restaurante Tierra y Cielo

\begin{tabular}{|c|c|c|}
\hline Premio & Institución & Comentarios \\
\hline $\begin{array}{l}\text { Premio Nacional del Emprendedor } \\
\text { en la categoría de “Mujer } \\
\text { Emprendedora” } 2014\end{array}$ & $\begin{array}{l}\text { Entregado por el presidente de la República } \\
\text { Enrique Peña Nieto }\end{array}$ & Premio nacional \\
\hline $\begin{array}{l}\text { Finalista en el Premio Nacional de } \\
\text { Calidad } 2013\end{array}$ & & Distinción \\
\hline $\begin{array}{l}\text { Reconocimiento Nacional por } \\
\text { Buenas Prácticas Sustentables } 2012\end{array}$ & $\begin{array}{l}\text { Entregado por la Canirac y Unilever Food } \\
\text { Solutions, agosto de } 2012\end{array}$ & $\begin{array}{l}\text { Reconocimiento } \\
\text { nacional }\end{array}$ \\
\hline $\begin{array}{l}\text { Reconocimiento de la Asociación } \\
\text { Mexicana de Mujeres Empresarias } \\
\text { AMMJE Delegación San Cristóbal }\end{array}$ & Enero de 2011 & $\begin{array}{l}\text { Reconocimiento } \\
\text { nacional }\end{array}$ \\
\hline $\begin{array}{l}\text { Premio a la Juventud "Javier Ruiz } \\
\text { Bonifaz" }\end{array}$ & $\begin{array}{l}\text { Entregado por el Club Rotario de San } \\
\text { Cristóbal de Las Casas, septiembre de } 2010\end{array}$ & $\begin{array}{l}\text { Reconocimiento } \\
\text { estatal }\end{array}$ \\
\hline $\begin{array}{l}\text { Reconocimiento a Mujeres } \\
\text { Empresarias de Chiapas } 2010\end{array}$ & $\begin{array}{l}\text { Entregado por el secretario de Turismo } \\
\text { Juan Carlos Cal y Mayor, octubre de } 2010\end{array}$ & $\begin{array}{l}\text { Reconocimiento } \\
\text { estatal }\end{array}$ \\
\hline $\begin{array}{l}\text { Premio al Mérito Empresarial } \\
\text { Restaurantero “José Peza Fragoso" } \\
\text { de Cocina Regional }\end{array}$ & $\begin{array}{l}\text { Entregado por el expresidente de la } \\
\text { República Felipe Calderón Hinojosa en el } \\
50 \text { aniversario de la Canirac, noviembre de } \\
2008\end{array}$ & Premio nacional \\
\hline
\end{tabular}

Fuente: Elaboración propia con base en http://www.tierraycielo.com.mx/

\section{Metodología}

Es un estudio cualitativo, con una aproximación a los procesos de empoderamiento femenino y toma de decisiones que implica acciones empresariales y, por tanto, de naturaleza multifacética en el comportamiento humano que no proporcionan esencialmente datos cuantitativos. La utilización de nuevos modelos explicativos propicia que nuevas metodologías emerjan, y el estudio de caso, en ese sentido, se debe tener en cuenta como una metodología que aborda los fenómenos contemporáneos dentro de la realidad de su contexto, donde lo ilimitado de este no es visible de manera precisa, por lo que tiene que ser aproximado desde diversas fuentes de evidencia (Villarreal y Landeta, 2010; Arias, 2003; Yin, 1989). Esto permite una mejor aproximación a los procesos, conductas y condiciones de la mujer frente a la gestión en ambientes competitivos, como el de los restaurantes. 


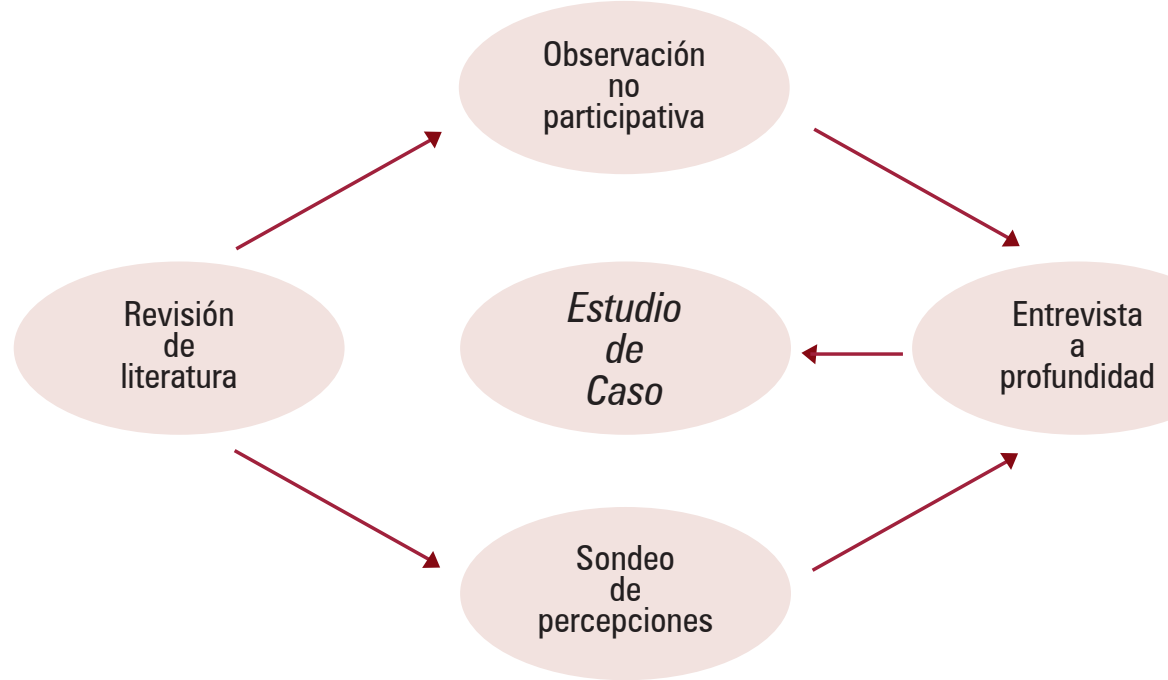

Fuente: Elaboración propia.

Figura 2. Aproximación metodológica del estudio de caso de Tierra y Cielo

Se utiliza como técnica de investigación una entrevista semiestructurada con la informante clave: su propietaria, quien ha sobresalido en el estado de Chiapas por contar con una visión culinaria destacada en la comida regional, ya que, con un enfoque sustentable en el restaurante Tierra y Cielo, ha logrado involucrar los rasgos representativos de la cultura chiapaneca.

En este sentido, el método de Rowlands (1998), con la tríada de las dimensiones y los rasgos que inhiben o potencian el empoderamiento (véase cuadro 3), se aplica en la entrevista a profundidad con un guion de 20 preguntas. El apartado sobre el tema "A. Dimensión personal" cuenta con seis preguntas; el del tema "B. Dimensión colectiva”, con ocho; y el del tema "C. Dimensión de las relaciones cercanas", con cinco. Los comentarios vertidos por la entrevistada se contrastan con las bases presentes de la tríada.

El análisis de los datos se realiza mediante el software Atlas.ti, en un análisis de redes semánticas, el cual facilita la elaboración de tramas entre los códigos identificados y sus vínculos, de manera que puedan visualizarse de forma gráfica las relaciones encontradas, apoyadas con la observación no participante.

Además, se tiene un sondeo entre los empleados del restaurante, con comentarios de su percepción sobre las acciones de gestión realizadas por la propietaria, los cuales se contrastan en busca de convergencias, se examinan mediante la red semántica y se relacionan con las tres dimensiones de Rowlands. Es decir, el análisis parte de cuatro niveles de influencia cercana a partir de su apreciación. 
CuAdro 3. Tríada del empoderamiento femenino de Rowlands

Tríada del

empoderamiento

femenino

Perspectiva

Está compuesta por la capacidad de la mujer para realizar acciones para el cambio, la identidad y la comprensión de su condición para alcanzar el empoderamiento y el desarrollo del sentido del ser y la confianza. Sostiene que la adquisición de conocimientos denota un rostro de empoderamiento, ya que permite acrecentar las habilidades para formular ideas y opiniones, participar e influir en nuevos espacios, otorgándoles mayores oportunidades de análisis y actuación.

Tiene un comportamiento similar al observado en la dimensión personal de acuerdo con la narrativa de la persona entrevistada, pero manifiesta una presencia en la comunidad, toda vez que a partir de sus acciones se está fomentando la participación y la organización colectiva.

Establece que esta es una consecuencia inevitable de la sinergia entre las dimensiones personal y colectiva de la mujer, y señala que es el área más difícil de cambiar debido a las resistencias que provocan en los participantes (familia, empleados, clientes, etc.) las expectativas de cambios empresariales.

Fuente: Elaboración propia con base en Rowlands (1998).

\section{Resultados y discusión}

Los resultados son producto de los comentarios vertidos durante la entrevista a profundidad, con respecto a las tres dimensiones de Rowlands, las cuales se han identificado con códigos presentes, o sea, la orientación del mensaje, y se interpretan en una red semántica.

\subsection{Primera: Dimensión personal}

La dimensión personal, de acuerdo con Rowlands (1998), está compuesta por la capacidad de la mujer para realizar acciones para el cambio, la identidad y la comprensión de su condición a fin de alcanzar el empoderamiento y el desarrollo del sentido del ser y la confianza. Sostiene que la adquisición de conocimientos denota un rostro de empoderamiento, ya que permite acrecentar las habilidades para formular ideas y opiniones, participar e influir en nuevos espacios, otorgándoles mayores oportunidades de análisis y actuación.

En este aspecto, es considerado como un componente de esta dimensión personal el conocimiento y las habilidades que posee la propietaria, así como el soporte que estas puedan aportar al restaurante. Dentro del conocimiento que la entrevistada manifestó poseer sobre el carácter empresarial dentro de su restaurante, es de remarcarse que pareciera estar plenamente apropiado como ayuda, apoyo y beneficio para ella en todas sus actividades. Lo anterior infiere un rasgo incipiente que posiblemente le permita integrarse 
a un proceso de empoderamiento, para posteriormente lograr los resultados deseados, como es la competitividad (véase figura 3).

a) Sobre la adquisición de conocimientos y habilidades, el liderazgo lo demuestra la propietaria con sus acciones de empoderamiento fundamentadas en la creación de valor en Tierra y Cielo, como indican Hernani y Hamann (2013), y su relación con la competitividad. Así lo señalan sus declaraciones, y se identifican los siguientes códigos semánticos: sociedad familiar, emprendimiento (idea de negocios), colaboración, gestión, socios familiares y capacitación.

La propietaria refiere que su entrada a la universidad a estudiar cocina fue por gusto y se reafirmó al llevar un proyecto que más tarde se fortalecería. Así, las condiciones de sociedad familiar y emprendimiento (idea de negocios) lo manifiestan:

Tierra y Cielo fue al principio mi proyecto de tesis, yo estudié la licenciatura en Hotelería en la Ciudad de México, y al principio funcionaba como un hotel, la casa es de mi familia, de mis papás, y con mis hermanos hicimos una sociedad para arrancar el hotel Tierra y Cielo, y ahora pues está el concepto de una hotelería más básica, porque todo ha evolucionado a lo largo de este tiempo, porque cuando iniciamos éramos básicamente un hotel de cuatro estrellas, y ahora es un restaurante gourmet de cocina internacional. Y ya poco a poco ha ido cambiando. Somos cinco socios, mis cuatro hermanos y yo, y la propiedad es de mis papás, todos somos parte de la familia.

Igualmente la líder muestra el interés por el emprendimiento mediante la colaboración y la gestión:

además he trabajado mucho con consultoría, siempre me ha gustado estar trabajando con cualquier idea que siento que me ayuda, y que sea un reto, que si voy a participar en el Premio Nacional del Emprendedor, pues eso implica que yo debo de tener al día mis reportes de ventas, de mercadotecnia, de recursos humanos, de medio ambiente, de participación en festivales y en congresos.

Y sostiene la condición de socios familiares y la capacitación constante al enfatizar las certificaciones logradas para mantener la calidad y servir como ejemplo para otras empresas.

b) Sobre las acciones emprendidas para el cambio, la identidad y la comprensión de su condición, en la entrevista se identifican los siguiente códigos semánticos: visión de cambio, colaboración, identidad, sustentabilidad, emprendimiento, capacitación, gestión.

La entrevistada reseña la importancia de los premios recibidos a partir de 2008 relacionados con la comida artesanal y las tradiciones, ante un compromiso con la Canirac local. De manera que:

para 2010 lanzamos el proyecto de la alta cocina regional, la que es de Chiapas, y para 2011, empezamos a trabajar otros distintivos, que es el del programa Cambia, es un programa dedicado al medio ambiente, y a fomentar esta parte de la empresa verde, empresa responsable, y al trabajar con eso. 


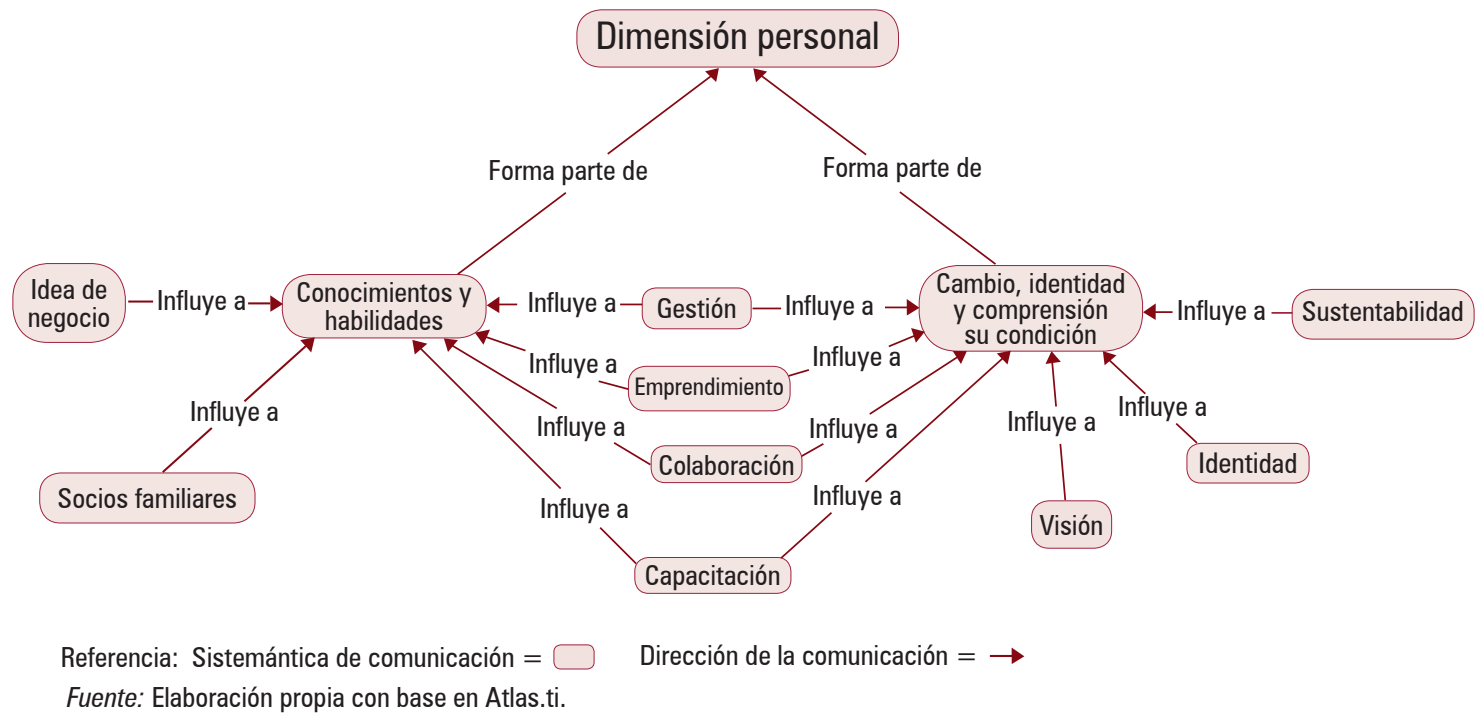

Figura 3. Red semántica de la dimensión personal

Así, la condición de emprendimiento, capacitación y gestión se manifiesta en el logro que revela la chef:

en 2014 [...] nos dieron el Premio Nacional del Emprendedor, pero ha sido un camino que hemos ido recorriendo poco a poco, adaptarse a estos distintivos y también tenemos las certificaciones, que para mí han sido muy importantes desde que estaba en la escuela, lo importante que es trabajar con higiene, con calidad, con normas, con procesos, porque así me enseñaron a estudiar.

La posición de la trayectoria de capacitación, identidad, gestión, se refrenda en su discurso de la comida regional y el trabajo con las cooperativas que se afianzan con las certificaciones y los distintivos de calidad. Como lo acota:

ahora tenemos como pilar a la comida regional, es lo principal de nuestro menú, a través del trabajo con las cooperativas, pero tenemos también la parte de calidad que para nosotros es muy importante manejar mejores procesos y cada vez tener más certificaciones y más distintivos que nos ayuden a ser mejores.

La alocución continúa en términos de calidad y la referencia al carácter chiapaneco, al utilizar insumos locales y regionales, evitando productos estandarizados internacionalmente (de cadena de supermercados, con productos congelados). De manera que el emprendimiento, la gestión y la capacitación están presentes:

Que cuando la gente piense en venir a Chiapas, piense en venir a Tierra y Cielo, y que eso se pueda compartir, y que tampoco sea eso de una moda.

La figura 3 acerca de la red semántica de la dimensión personal sintetiza el escenario: a) sobre la adquisición de conocimientos y habilidades, y b) sobre las acciones emprendidas para el cambio, la identidad y la comprensión de su condición. 


\subsection{Segunda: Dimensión colectiva}

Dentro de la dimensión colectiva del empoderamiento mencionada por Rowlands (1998), se identifica un comportamiento similar al observado en la dimensión personal, de acuerdo con la narrativa de la entrevistada. Aunado a ello, se manifiesta una presencia participativa dentro de la comunidad, toda vez que a partir de sus acciones se está fomentando la participación y la organización colectiva.

Se considera que lo anterior se debe a que las acciones realizadas por la propietaria sirven de apoyo a las redes constituidas por los pequeños productores para enfrentar sus condiciones de extrema pobreza (redes que fundamentalmente operan a través de intercambios), y fortalecen la participación comunitaria mediante, por ejemplo, proyectos productivos colectivos, además de que fomenta contactos con los empresarios de la ciudad y de otras localidades.

A partir de la observación no participante, se percibe una diferencia de opinión entre la chef y las instituciones gubernamentales, pues existe inconformidad con las políticas públicas existentes. En este sentido, manifiesta que el gobierno no está fomentando la actividad restaurantera dentro de la comunidad, ni tampoco promueve la unidad para la creación de proyectos productivos $u$ otras alternativas colectivas que eventualmente permitieran el beneficio socioeconómico en la comunidad (véase figura 4).

a) Sobre el fomento a la participación, se detectan los siguientes códigos semánticos: identidad, proveeduría local, promoción, compromiso social, colaboración, visión de cambio, competitividad, capacitación.

Los códigos semánticos se encuentran entrelazados; es así como la entrevistada, a partir de la identidad, la proveeduría local y la promoción, explica:

entonces me da mucho gusto que cocineros mexicanos estén en las listas de los mejores exponentes del mundo, están utilizando ingredientes de Ocosingo, de los Altos de Chiapas, de Tascalate, entonces ya le están dando esta promoción a los productos chiapanecos, y es la fórmula de llevar la cocina de Chiapas hacia las mejores cocinas de México.

Continúa con su exposición, remarcando el compromiso social de su parte, en cuanto al apoyo a los artesanos y las cooperativas, en el sentido de reflejarlo al visitante de San Cristóbal. Esto es, lograr, en el ámbito de gobierno estatal, programas de apoyo para mejorar su calidad de vida. La sensibilización a los entornos de gobierno mediante el restaurante ha cambiado al paso del tiempo, como lo comenta. Ahora se cuenta con:

el sistema de encuesta a clientes, es una parte muy importante que nos permite ver en qué estamos fallando, o en qué estamos diciendo cosas distintas, porque a veces no es que falles, sino que los clientes esperan algo diferente a lo que tenían en su mente antes de venir a Tierra y Cielo. 
La visión de cambio, a partir de la propietaria, se ha modificado en el transcurso de la operación del hotel-restaurante/restaurante-hotel, y explica que los cambios se han dado del servicio personalizado tradicional con comida regional, a innovaciones no solo en el servicio sino en los platillos tradicionales con el apoyo regional:

la clave está en hacer las cosas con calidad, con este arraigo a nuestras raíces y con este apoyo a nuestros productores y a nuestros colaboradores, a nuestros proveedores, que ya son nuestros colaboradores. Nosotros queremos que mucha gente se sume a lo que hacemos.

b) Sobre el fomento a la organización colectiva, en la entrevista se reflejan los siguientes códigos semánticos, que interactúan en el discurso: colaboración, compromiso social, calidad, identidad, capacitación, promoción, gestión, visión de cambio y sustentabilidad.

La consultada, en términos de inclusión, habla de "nosotros", al mencionar el trabajo de colaboración con la Canirac y la Confederación Patronal de la República Mexicana (Coparmex) en el proyecto llamado Marca Chiapas. La idea se configura en términos de calidad y compromiso social, sin dejar de insistir en la identidad:

empiezo a trabajar con cooperativas, con asociaciones, con los tianguis de cocina que hay cercana, con esa parte de ver cómo nosotros podemos promover a los pequeños productores de Chiapas, capacitarlos también, para que puedan acceder a la marca Chiapas, que es una marca estatal, que certifica a estos productores que tienen cierta calidad, y sobre todo les ayuda a trabajar con una manera en la que ellos puedan distribuir a restaurantes, puedan facturar y ser empresas formales.

El trabajo de los artesanos y de los productores lo tiene en la visión y misión de Tierra y Cielo: el bordado de San Juan Chamula, el cacao de Choconuztlo, el queso bola de Ocosingo, o el pescado de La Encrucijada; detrás de cada producto están las familias chiapanecas. Y considera la visión de cambio mediante la colaboración:

Ya cosas más generales, tomamos las decisiones en conjunto con los hoteleros, los restauranteros, en redes de empresarios, con las asociaciones, con las cámaras, participando directamente en las mesas y en los consejos, porque me interesa, porque estoy convencida de que para cambiar algo tienes que participar.

En este orden de ideas, el restaurante es un enclave en la sociedad, el cual transmite con elocuencia mediante el empoderamiento femenino:

queremos que sea una empresa líder que promueva Chiapas, que la gente que piense en Chiapas, piense en venir a Tierra y Cielo, pero que también al final Tierra y Cielo sea punta de lanza en muchas cosas, como el programa ambiental, como con las alianzas con los productores, como con el trabajar con las comidas de las comunidades cercanas, como promover a las zonas protegidas de la biosfera.

La figura 4 en torno a la red semántica de la dimensión colectiva comprime los conceptos a) sobre el fomento a la participación y b) sobre el fomento a la organización colectiva y 
las directrices en la posición colectiva. Asimismo, incorpora consideraciones concurrentes con Millán y Marín (2014), pues se asocian con la competitividad, ya que se ha logrado una toma de decisiones de manera conjunta. Esta situación impacta en los involucrados y en su posición en condiciones prioritarias para la organización.

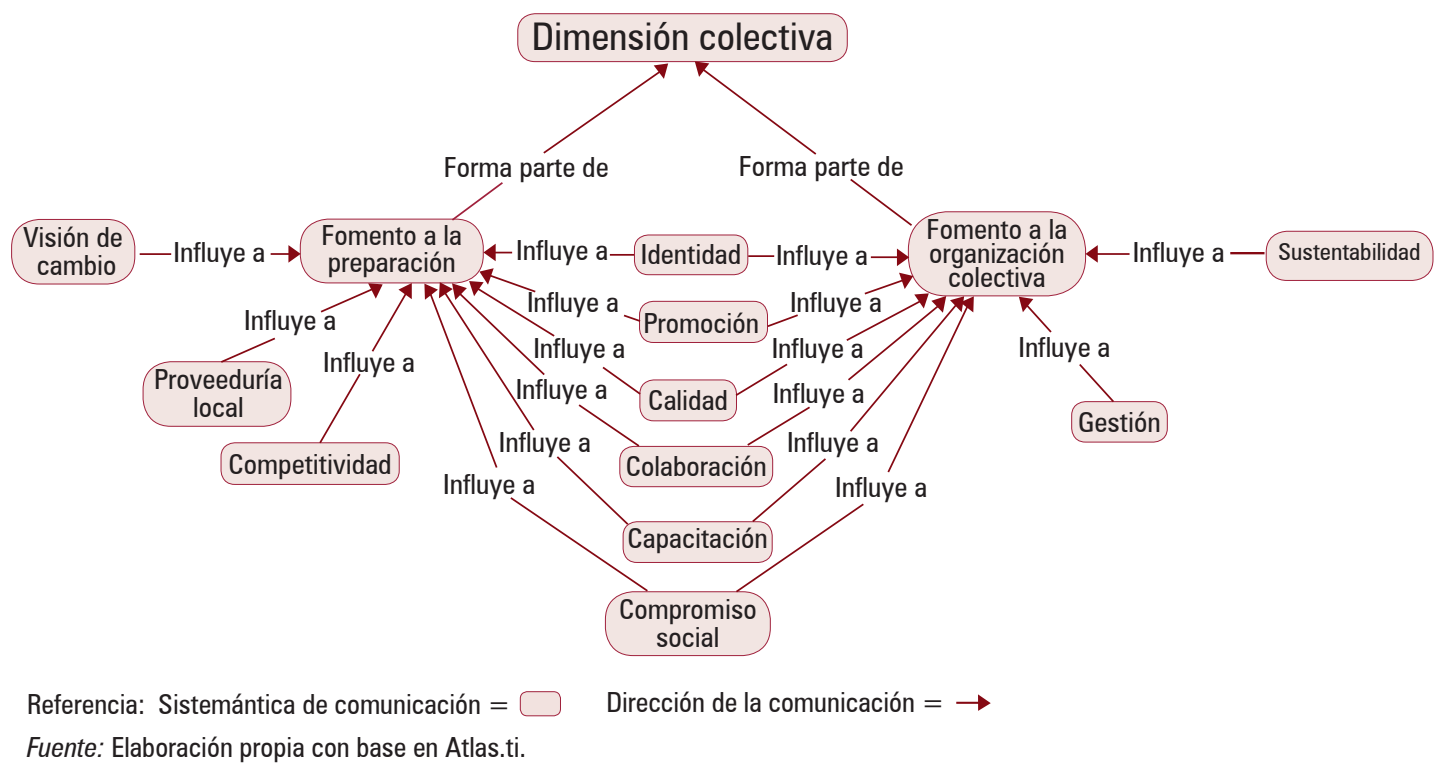

FiguRA 4. Red semántica de la dimensión colectiva

\subsection{Tercera: Dimensión de las relaciones cercanas}

En cuanto a esta tercera dimensión del empoderamiento, concerniente a las relaciones cercanas, Rowlands (1998) establece que esta es una consecuencia inevitable de la sinergia entre las dimensiones personal y colectiva de la mujer. Además, señala que es el área más difícil de cambiar debido a la resistencia que provocan en los participantes (familia, empleados, clientes, etc.) las expectativas de cambios empresariales.

La entrevistada revela que ha experimentado cambios sustanciales en las relaciones con su pareja, familiares, empleados y clientes, entre otros, a partir de su evolución como empresa en busca de ser más competitiva. Las respuestas dadas y sus opiniones giran en torno a que este (el restaurante) es una ayuda y un beneficio para todos los involucrados. Los testimonios dejan entrever que tampoco se han producido conflictos importantes por parte de estos respecto al fin que se debe perseguir y que, por el contrario, lo que domina es un discurso de comprensión y condescendencia. Este hecho es un indicador de la gestión empresarial de la entrevistada, y al tiempo que puede favorecer su empoderamiento, también lo inhibe fundamentalmente al reproducir en el discurso y en la práctica las principales premisas de las normas hegemónicas de género (véase figura 5). 
a) Sobre las relaciones con su familia, se identifican los siguiente códigos semánticos: gestión, emprendimiento, sociedad familiar, colaboración, identidad, recursos y visión de cambio.

En la entrevista se comenta sobre el bien familiar, en términos de gestión, emprendimiento y sociedad familiar. La responsabilidad recae en sí misma, lo que implica dificultad, compromiso y libertad:

luego por el bien familiar decidimos que nada más yo iba a llevar la dirección de la empresa, y me quedé haciendo todo prácticamente sola, y fue muy complicado, muy difícil, pero también es algo que te da el poder elegir, el tener la libertad de tomar cada decisión, el no pedir permiso, y hacer algo, y entonces pues ha sido muy bueno.

La sociedad familiar exige, pero al definir una estructura de trabajo la directora distribuye la carga de responsabilidad y otorga condiciones de identificación con la empresa. De esta manera, los colaboradores (familia y empleados) se cautivan con su labor:

depende mucho de tener claro la función de cada uno, qué es lo que hace cada quien y que eso se respete, y también como empresario ver si puedes o no trabajar con alguien más, si estás dispuesto a tomar decisiones en conjunto, a tener muy clara también la parte del dinero, de cómo se reparte y cuándo se reparte, y todo implica si todos le apuestan a que la empresa siga creciendo.

b) Sobre las relaciones con los empleados y otros involucrados, se cuenta con los siguientes códigos semánticos: identidad, colaboración, compromiso social, capacitación, calidad, promoción, gestión, recursos y sin apoyo gubernamental.

Acerca de la relación con los empleados y otros involucrados, la directora apunta que es una elección estatal, es decir, 95 \% de los trabajadores son chiapanecos, en especial de comunidades cercanas a San Cristóbal, que por lo general hablan algún dialecto:

Yo misma he elegido un perfil de gente con la que estoy acostumbrada a trabajar, por ejemplo, en la cocina trabajo con señoras, a veces tengo algunos jóvenes que hacen prácticas, pero por lo general no. Con los hombres al revés, para los meseros que sean jóvenes, porque a los señores les costaba trabajo, no querían cambiar, toda la vida le he hecho así, nunca lo he hecho mal, no voy a caer en esta parte de que no íbamos por el mismo camino, pero con los chavos que están estudiando, que tienen ganas, que quieren sacar un dinero extra para terminar sus estudios.

$Y$ afirma:

entonces también trabajamos esta parte de capital humano, en donde se certifiquen con los mismos distintivos que nosotros tenemos, y más que se certifiquen ellos, gente que entró de ayudante y ahora son baristas, tenemos gente que ganó "El capitán de meseros del siglo xxi", y gente que ha hecho carrera dentro de la empresa, pero que también ha hecho carrera en Chiapas.

El compromiso de la chef se encuentra en la colaboración, promoción, compromiso social, y capacitación constante: 
una persona que tenía conmigo siete años ya fue a representar a Chiapas en cocina tradicional, hace 15 días, al Foro Mundial de la Cocina Mexicana, en Puebla, entonces ella realmente no sabía nada de cocina tradicional, ella era una indígena que entró a trabajar conmigo de lavalozas, luego subió a ayudante, luego subió a cocinera, luego fue atendiendo recetas, algunas recetas las creamos en conjunto, las trabajamos, y ahora fue a representar a Chiapas como cocinera tradicional del estado.

Su gestión se encuentra presente en las reuniones de trabajo con su equipo de colaboradores, pues las vicisitudes, desde la visión de cambio social, se ubican en las jefaturas de área y el gestor de calidad, de modo que las decisiones se toman al interior del grupo de forma conciliatoria. Pero en el entorno externo es diferente y exhibe:

estas leyes o estándares que hay por parte del gobierno no están bien estructuradas ni tampoco están a favor de los empresarios restauranteros de simplificarles las cosas o que te motiven a hacerlo negocio informal cuando ya te cansaste.

La figura 5 agrupa las condiciones de la dimensión de las relaciones cercanas: a) sobre las relaciones con su familia, y b) sobre las relaciones con los empleados y otros involucrados. En la figura también se observan estrategias de gestión de personal que fortalecen esta dimensión como se indica: "se desean trabajadores con disposición laboral, además que susciten calidad en el servicio, también la empresa deberá corresponder a dicho esfuerzo y la satisfacción de necesidades a los trabajadores, al propiciar calidad de vida” (Varela Juárez, Cuevas Contreras y Salmerón Manzanares, 2015, p. 67).

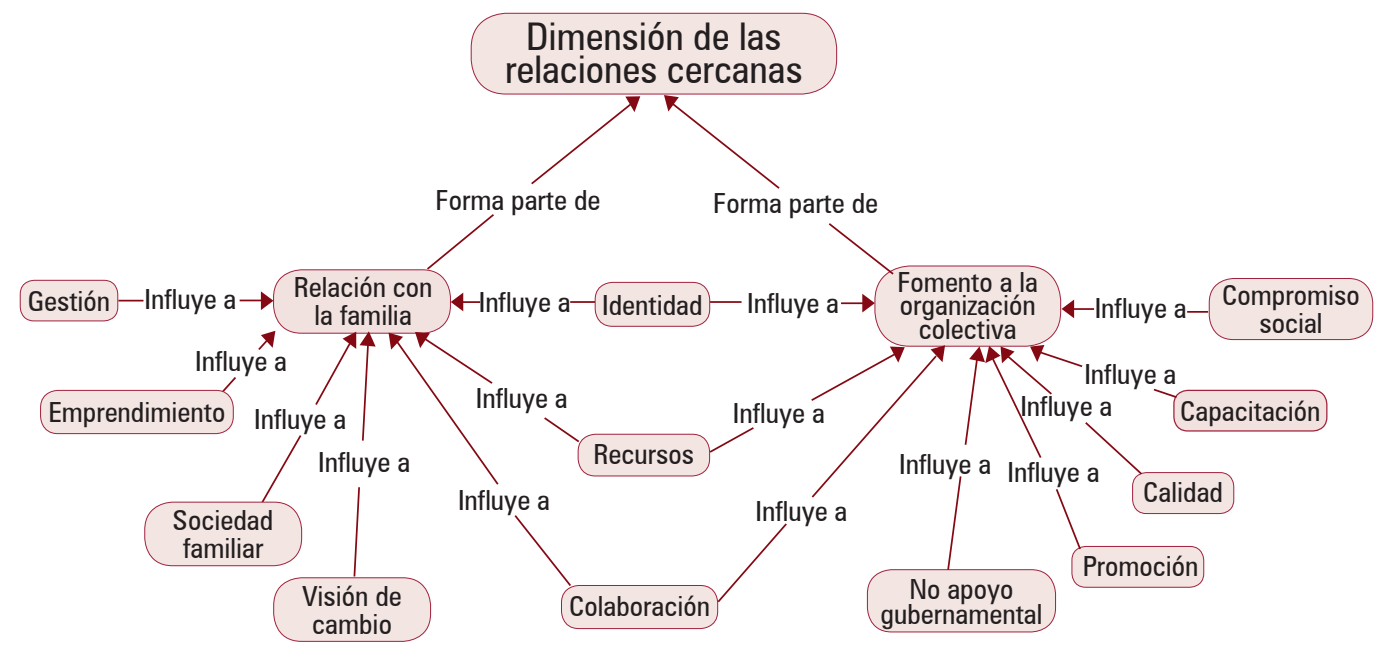

Referencia: Sistemántica de comunicación =

Dirección de la comunicación $=\rightarrow$

Fuente: Elaboración propia con base en Atlas.ti.

Figura 5. Red semántica de la dimensión de las relaciones cercanas 
El sondeo entre los empleados del restaurante (figura 6) refleja su percepción sobre las acciones del empoderamiento femenino. Los comentarios presentan convergencias en las tres dimensiones de Rowlands, en la red semántica.

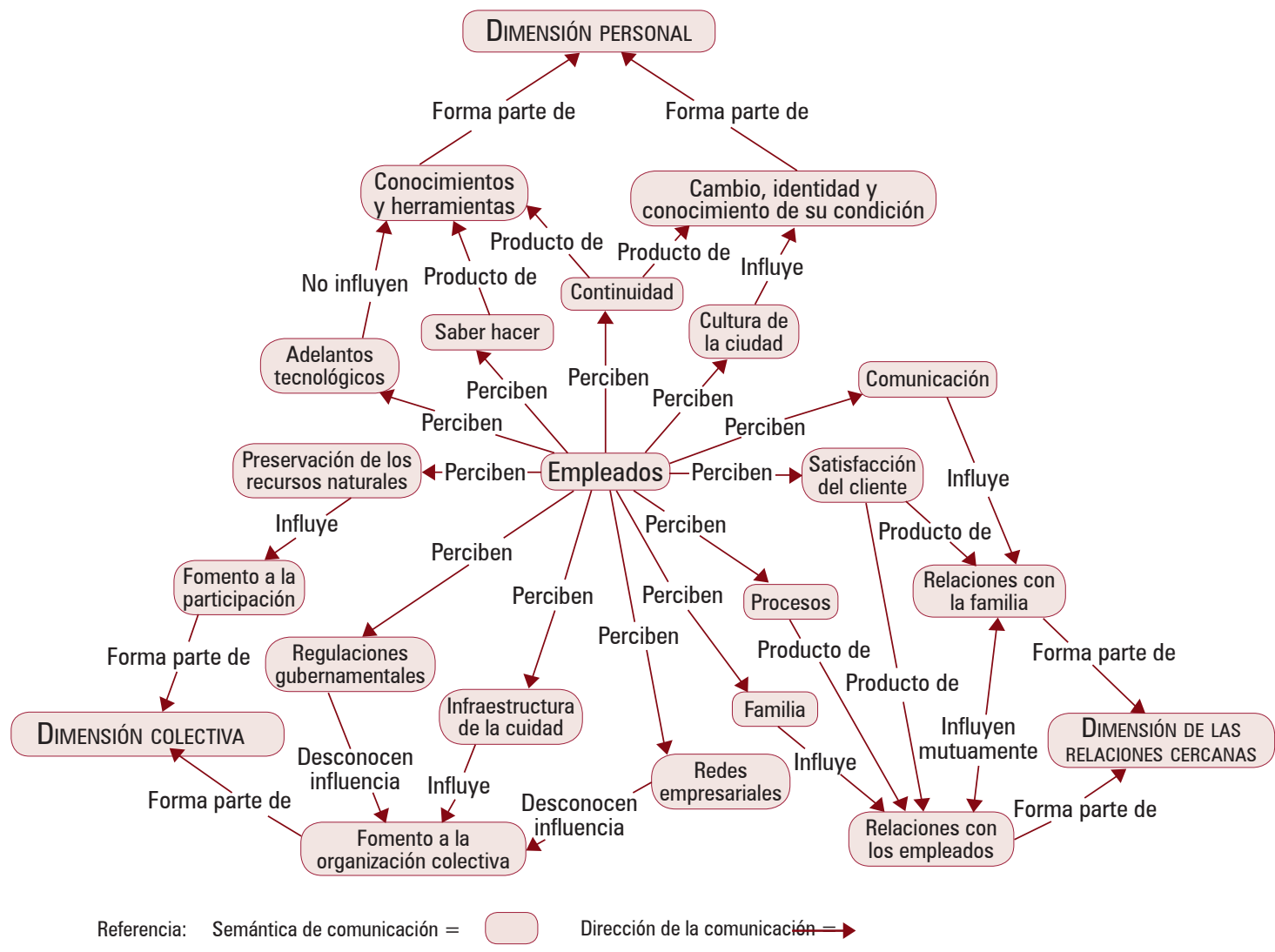

Fuente: Elaboración propia con base en Atlas.ti.

Figura 6. Red semántica de los comentarios de empleados

El cuadro 4 presenta los códigos identificados en los comentarios vertidos por los empleados; asimismo se incorpora la interpretación, la cual permite el vínculo entre su percepción y las dimensiones (personal, colectiva y de relaciones cercanas).

La mirada de los empleados (figura 7) es significativa ante su percepción del empoderamiento femenino y su liderazgo. Esta mirada se plasma en 12 códigos de interpretación vertidos en los comentarios. En este sentido, el análisis parte de cuatro niveles de influencia semántica y su cercana a partir de su apreciación.

El primer nivel de análisis se encuentra configurado por 12 posiciones semánticas $y$, de esta forma, estimula el segundo nivel con enfoques en: 1) Infraestructura de la ciudad; 2) Preservación de los recursos naturales; 3) Cultura de la ciudad; 4) Saber hacer; 5) Adelantos tecnológicos; 6) Redes empresariales; 7) Regulaciones gubernamentales; 8) Satisfacción del cliente; 9) Procesos; 10) Continuidad; 11) Familia; y 12) Comunicación. 


\section{J. González-Macías · T. J. Cuevas-Contreras · I. Zizaldra-Hernández}

Mientras, el tercer nivel emerge de derecha a izquierda: 1) Conocimientos y habilidades; 2) Cambio, identidad y conocimiento de su condición; 3) Relaciones con la familia; 4)

CuAdro 4. Comentarios de los empleados sobre la gestión de la propietaria

\begin{tabular}{|c|c|}
\hline Códigos semánticos & Interpretación \\
\hline Infraestructura de la ciudad & $\begin{array}{l}\text { Percepción de adecuado aprovechamiento de la infraestructura que } \\
\text { brinda la ciudad. Influye para el fomento de la organización colectiva. }\end{array}$ \\
\hline $\begin{array}{l}\text { Preservación de los recursos } \\
\text { naturales }\end{array}$ & $\begin{array}{l}\text { Percepción de que los procesos no contaminan el medio ambiente. } \\
\text { Esto influye al fomento a la participación. }\end{array}$ \\
\hline Cultura de la ciudad & $\begin{array}{l}\text { Percepción de lucha y trabajo por una ciudad muy propensa } \\
\text { culturalmente para la actividad restaurantera. Esto influye en el } \\
\text { cambio, la identidad y el conocimiento de su condición. }\end{array}$ \\
\hline Saber hacer & $\begin{array}{l}\text { Percepción de un dominio del saber hacer de las actividades } \\
\text { del restaurante. Esto es producto de todos sus conocimientos y } \\
\text { habilidades. }\end{array}$ \\
\hline Adelantos tecnológicos & $\begin{array}{l}\text { Percepción de que los adelantos tecnológicos no son necesarios para } \\
\text { brindar buen servicio y excelentes platillos. Estos no influyen en sus } \\
\text { conocimientos y habilidades. }\end{array}$ \\
\hline Redes empresariales & $\begin{array}{l}\text { Percepción de } 40 \% \text { de conocimiento de convenios con proveedores } \\
\text { locales y el restante } 60 \% \text { de los empleados manifestó desconocerlo. } \\
\text { Esto es un desconocimiento de la influencia sobre el fomento a la } \\
\text { organización colectiva. }\end{array}$ \\
\hline $\begin{array}{l}\text { Regulaciones } \\
\text { gubernamentales }\end{array}$ & $\begin{array}{l}\text { Percepción de } 85 \% \text { de desconocimiento sobre las regulaciones } \\
\text { gubernamentales y de } 15 \% \text { que no ayudan. Esto es un } \\
\text { desconocimiento de la influencia en el fomento a la organización } \\
\text { colectiva. }\end{array}$ \\
\hline Satisfacción del cliente & $\begin{array}{l}\text { Percepción de un excelente servicio al cliente. Esto es producto de las } \\
\text { relaciones estrechas con familia y empleados. }\end{array}$ \\
\hline Procesos & $\begin{array}{l}\text { Percepción de adecuados procesos. Esto es producto de las } \\
\text { relaciones estrechas con empleados. }\end{array}$ \\
\hline Continuidad & $\begin{array}{l}\text { Percepción de continuidad del restaurante. Esto es producto de } \\
\text { los conocimientos y habilidades, así como del cambio, identidad y } \\
\text { conocimiento de su condición. }\end{array}$ \\
\hline Familia & $\begin{array}{l}\text { Percepción de un ambiente de familia. Esto influye sobre las relaciones } \\
\text { con los empleados. }\end{array}$ \\
\hline Comunicación & $\begin{array}{l}\text { Percepción de excelente comunicación. Esto influye en las relaciones } \\
\text { con los empleados. }\end{array}$ \\
\hline
\end{tabular}

Fuente: Elaboración propia. 


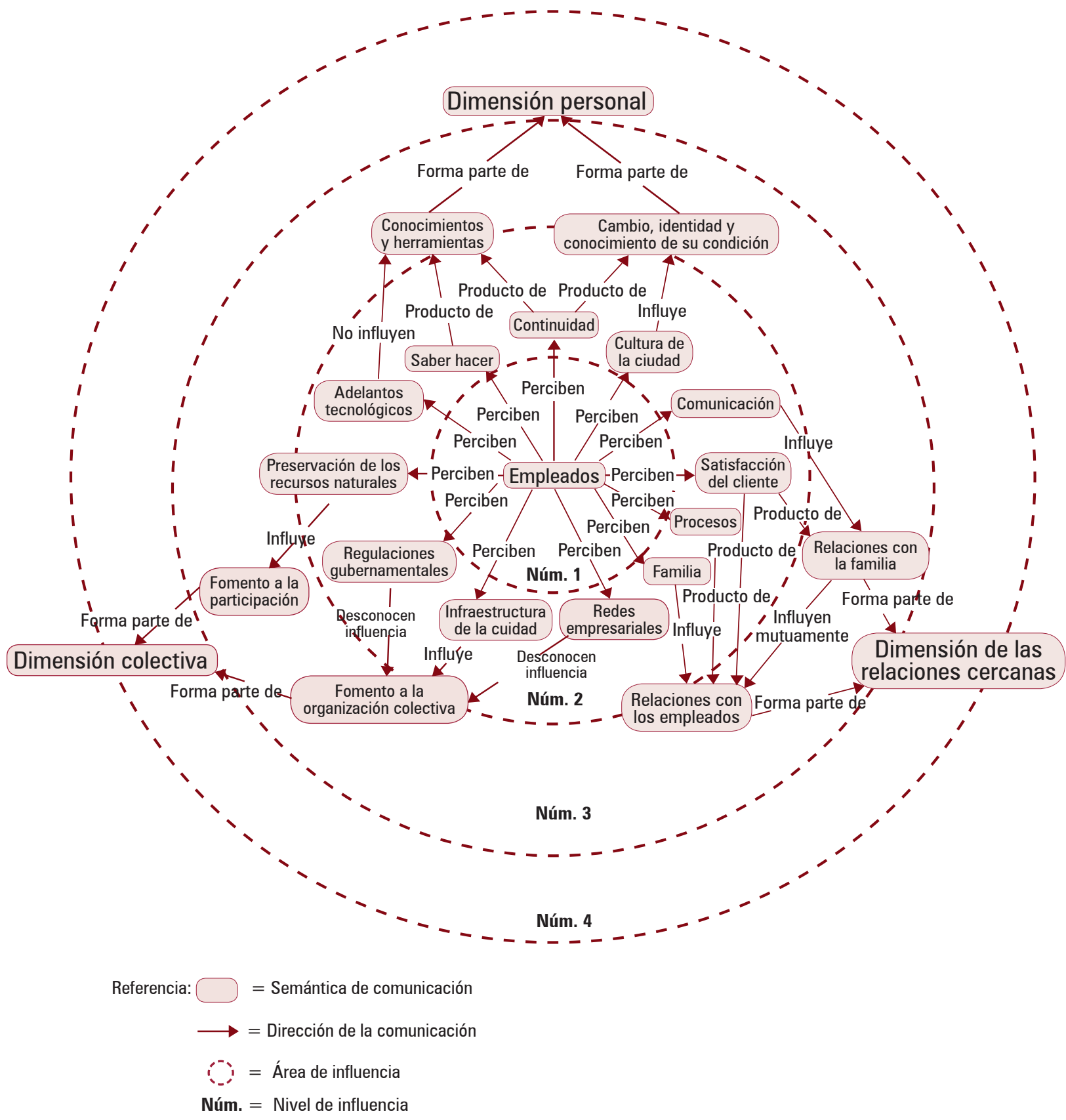

Fuente: Elaboración propia con base en Atlas.ti.

Figura 7. Mirada de los empleados en Tierra y Cielo 
Relaciones con los empleados; 5) Fomento a la organización colectiva; y 6) Fomento a la participación. De hecho, es revelador el manejo de niveles de influencia. En el cuarto nivel, la dimensión personal coincide con la mirada de los empleados, y se engarza, mediante los conocimientos y habilidades, con el cambio, identidad y conocimiento de su condición. Estas son interacciones relacionadas con adelantos tecnológicos, saber hacer, continuidad y cultura de la ciudad.

Por su parte, el fomento a la organización y la participación colectiva estimulan la dimensión colectiva, acompañados de la relación familiar y de los empleados, además del producto de preservación, apoyo en regulaciones, infraestructura de la ciudad y redes empresariales, en cuanto a cómo las relaciones cercanas se encuentran a una distancia similar de la familia, los procesos, la satisfacción del cliente y la comunicación, mediante la relación con los empleados y la familia.

A pesar de que la colaboración gubernamental es exigua, este escenario resulta motivante, de manera que las alianzas estratégicas son de vital importancia (Olguín Negrete, Cuevas Contreras y Loera Anchondo, 2016; Leguísamo Guevara, 2016). Esta situación cohesiona a los actores, y el ánimo de colaboración y cooperación se respalda.

\section{Conclusión}

Frente a las acciones de empoderamiento femenino y su liderazgo, el ambiente de los restaurantes ha sido un enclave en su desarrollo. En este contexto, el enlace entre competitividad y sustentabilidad se compromete con lo glocal, pues el mercado actual no solo está en la globalización, sino en una intensa competencia para mantener la ventaja competitiva (Dressler y Varela, 2004). Así, lo femenino, ante el reto de un liderazgo empresarial, se enfoca en el desarrollo de procesos comunitarios, que establecen una estrategia frontal contra las carencias (Erazo et al., 2014). Y se alza con acciones multifacéticas al observar respeto a los integrantes sociales, mediante lo legal y la acentuación en la colaboración y la cooperación de los familiares y empleados.

El restaurante Tierra y Cielo, en el centro de la ciudad de San Cristóbal de Las Casas, Chiapas, cuenta con una excelente apariencia externa, rodeado de un ambiente de la época colonial y las calles anexas limpias en general, pero con banquetas muy reducidas, y ruidosos alrededores por la noche. El edificio en donde se ubica tiene buen mantenimiento, pues, aunque es antiguo, se ve renovado y adaptado con instalaciones adecuadas, considerando la conciliación entre el hotel y el restaurante como parte de los servicios que se brindan a los visitantes. De manera que los espacios son reducidos, pero con un patio para mesas y sillas, adornado con artesanías, plantas y flores de la región, en donde se percibe la influencia femenina. Mientras, el estacionamiento es una ventana de oportunidad de mejora, ya que se encuentra retirado del establecimiento, y aunque se localiza en el centro de la ciudad, tiene lugar para pocos vehículos.

La impronta en el restaurante se refleja también en los productos locales y los elementos de identidad cultural, y se demuestra la imagen de liderazgo femenino. Esta huella 
es tangible en las condiciones internas, que superan la imagen externa, al contar con un ambiente que invita a departir, aun y lo limitante del espacio. Sus instalaciones están cuidadas, limpias y muy coloridas. Con mobiliario apropiado y cómodo, además de una adecuada presentación. Aportando un lugar acogedor y cálido, a manera de hogar. El ambiente del área de espera reafirma el toque femenino, al utilizar adornos y productos típicos (decoración floral y artesanías de la región) y de marca propia a la venta.

Las tres dimensiones exploradas de la propuesta de Rowlands (1998) en lo personal, colectivo y de las relaciones cercanas son patentes en los procesos y conductas condicionantes de acciones empresariales femeninas. El interior del restaurante confirma su administración sustentable, con un montaje conveniente de una casona de principios del siglo xx. Aunque la decoración es austera, se enfoca en resaltar las tradiciones y la cultura local, con un menú equilibrado incluso en los precios de los platillos. La recepcionista es amable, simpática, agradable, y ubica a los comensales donde estos lo solicitan. Está apoyada con el personal de servicio (mesero), que es agradable, considerado, y está informado del menú. Entonces se aprecia el compromiso, al brindar atención esmerada, explicación de los platillos y recomendaciones sobre bebidas. De tal modo, se demuestra un liderazgo en la gestión, al reclutar personal técnicamente responsable y comprometido con su entorno.

Los tiempos del servicio son acordes al menú, con platillos originales y porciones adecuadas. Sin espera prolongada, entre la orden y la llegada de platillos y bebidas. El periodo más largo corre al ordenar el platillo principal, sin embargo, se requiere mayor presencia de la propietaria en el área de servicio, ya que su atención haría más placentera la estancia. Aunque los tiempos son adecuados, es recomendable dedicarle un tiempo especial a la llegada y a la salida de los comensales. Actualmente, el cobro y la despedida se realizan con una amabilidad genérica. En el transcurso de la experiencia se acompaña con música en vivo, lo que confiere distinción al lugar, atribuible a las comisiones existentes.

Por último, el posicionamiento ganado en un ecosistema tradicionalmente masculino, pero cada vez más llano, que se beneficia con su accesibilidad a las incursiones del empoderamiento femenino, se encuentra presente en la gestión de Tierra y Cielo, el cual se reafirma con su perspectiva empresarial competitiva e innovadora.

\section{Fuentes consultadas}

Arias, M. (2003). Metodologías de investigación emergentes en economía de la empresa. Papers Proceedings, 17, 19-28.

Bianco, C. (Marzo, 2007). ¿De qué hablamos cuando hablamos de competitividad? (Documento de Trabajo, núm. 31). Centro de Estudios sobre Ciencia, Desarrollo y Educación Superior.

Buendía-Martínez, I. y Carrasco, I. (2013). Mujer, actividad emprendedora y desarrollo rural en América Latina y el Caribe. Cuadernos de Desarrollo Rural, 10(72), 21-45.

Camberos, M. (2011). Empoderamiento femenino y políticas públicas, una perspectiva desde las representaciones sociales de género. Entramado, 7(29), 40-53. 
Canirac. (2014). Dimensiones de la Industria Restaurantera. Cifras de la Industria Restaurantera para maximar su potencial económico. México: Autor/Instituto Nacional de Estadística y Geografía. Recuperado de http://canirac.org.mx

Casique, I. (2010). Factores de empoderamiento y protección de las mujeres contra la violencia. Revista Mexicana de Sociología, 72(1), 37-71.

Centro de Estudios para el Desarrollo Municipal y Políticas Públicas. (2014). Ciudades rurales sustentables: referentes para la formulación del Plan Maestro. Tuxtla Gutiérrez: Universidad Autónoma de Chiapas.

Cobo Quesada, F. B., Hervé, A. y Aparicio Sánchez, M. S. (2009). El sistema turístico en clave de marketing relacional: el factor relacional. Anuario Jurídico y Económico Escurialense, XLII, 419-442.

Dressler, G. y Varela, R. (2004). Administración de recursos humanos. Enfoque latinoamericano. México: Pearson Educación.

Durón, C. (2012). El restaurante como empresa. México: Trillas.

Erazo, M., Jiménez, M. y López, C. (2014). Empoderamiento y liderazgo femenino; su papel en la autogestión comunitaria en el corregimiento El Hormiguero-Valle del Cauca. Avances en Psicología Latinoamericana, 32(1), 149-157.

Franco, A. (2012). Administración de la empresa restaurantera. México: Trillas.

Hernani, M. y Hamann, A. (2013). Percepción sobre el desarrollo sostenible de las MyPE en Perú. Revista de Administración de Empresas, 53(3), 290-302.

Instituto de Población y Ciudades Rurales. (2013). Programa de ciudades rurales sustentables. Tuxtla Gutiérrez: Gobierno del Estado de Chiapas.

Instituto Nacional de Estadística y Geografía. (2015). Sistema Automatizado de Información Censal. Recuperado de http://www.inegi.org.mx

Kabeer, N. (1999). Resources, agency, achievements: Reflections on the measurement of women's empowerment. Development and Change, 30, 435-464.

La Rovere, R. y Hasenclever, L. (2010). Innovación, competitividad y adopción de tecnologías de la información y de la comunicación en pequeñas y medianas empresas: algunos estudios de caso sobre Brasil. Río de Janeiro: Universidad Federal de Río de Janeiro, Instituto de Economía.

Leguísamo Guevara, M. R. (Enero, 2016). Economía popular y solidaria para el mejoramiento del comercio justo de productos de cacao de aroma. Caso: Asociación Artesanal de Mujeres Emprendedoras San Plácido - Portoviejo (Tesis de magíster en Gestión para el Desarrollo Local Comunitario). Pontificia Universidad Católica del Ecuador, Escuela de Trabajo Social.

León, M. (2007). Poder y empoderamiento de las mujeres. Bogotá: Tercer Mundo Editores.

Lino, S. (2013). Víctima, detective y femme fatale: En busca de estrategias de empoderamiento femenino ante la inmigración en la novela negra española. L'érudit Franco-Espagnol, 4, 65-85.

Manucci, M. (2010). Contingencias. 5 desafíos de cambio para una nueva década. Bogotá: Norma.

Matthaei, J. (2010). Más allá del hombre económico: Crisis económica, economía feminista, y la economía solidaria. Cayapa, Revista Venezolana de Economía Social, 10(19), 65-80.

Millán, S. y Marín, M. (2014). Competitividad de las empresas familiares del sector alimentos de tipo gourmet de la ciudad de Ensenada, Baja California. Global Conference on Business and Finance Proceedings, 9(1), 1055-1060. 
Montero, M. (2003). Teoría y práctica de la psicología comunitaria. Buenos Aires: Paidós.

Olguín Negrete, B. R., Cuevas Contreras, T. J. y Loera Anchondo, E. (2016). Colaboración entre lo público y lo privado en la imagen del destino de Hermosillo Sonora. CULTUR: Revista de Cultura e Turismo, 10(3), 6-21.

Pérez, J. y Cortés, J. (2007). Barreras para el aprendizaje organizacional: Estudio de casos. Pensamiento y Gestión, 22, 256-282.

Porter, M. (1985). Competitive Advantage: Creating and Sustaining Superior Performance. Nueva York: Free Press.

Porter, M. (1990). The Competitive Advantage of Nations. Nueva York: Free Press.

Porter, M. (2004). Ventaja competitiva. México: CECSA.

Román, L. (2000). Acumulación de la pobreza y política social. En L. Valencia et al. (coords.), Los dilemas de la política social, ¿cómo combatir la pobreza? México: Amaroma Ediciones.

Rowlands, J. (1996). Empowerment Examined: An Exploration of the Concepts and Practice of Women's Empowerment in Honduras, in Questioning Empowerment. Working with Women in Honduras (Tesis doctoral). Universidad de Durham, Departamento de Geografía.

Rowlands, J. (1998). Empoderamiento y mujeres rurales en Honduras: un modelo para el desarrollo. En M. León (comp.), Poder y empoderamiento de las mujeres (pp. 213245). Bogotá: Tercer Mundo Editores.

Sáez, G., Valor-Segura, I. y Expósito, F. (2012). ¿Empoderamiento o subyugación de la mujer? Experiencias de cosificación sexual interpersonal. Psychosocial Intervention, 21(1), 41-51. Recuperado de http://dx.doi.org/10.5093/in2012v21n1a9

Saldívar González, S. J., García Rivera, B. R., Valenciana Moreno, N. y Roa Rivera, R. O. (2012). Competitividad y gestión de las Pymes. Global Conference on Business and Finance Proceedings, 7(2), 1152-1156.

Trujillo Rincón, J. (Noviembre, 2015). Pymes más competitivas para la creación de más empleos. Análisis de la cadena de valor del sector turístico de San Cristóbal de Las Casas, Chiapas, México. Organización Internacional del Trabajo. Recuperado de http://www.ilo.org

Varela Juárez, R., Cuevas Contreras, T. y Salmerón Manzanares, S. (2015). Efectos de la propina en la socioeconomía y en el ser humano. Noésis, 24(número especial 1), 49-68. Recuperado de http://www.revistanoesis.net/47-es-1/4/

Vázquez-Luna, D., Mortera, D., Rodríguez-Orozco, N., Martínez, M. y Velázquez, M. (2013). Organización comunitaria de mujeres: del empoderamiento al éxito del desarrollo rural sustentable. La Ventana, 23, 262-288.

Villafuerte, D. (2011). Integraciones comerciales en la frontera sur. México: Universidad Nacional Autónoma de México.

Villarreal, O. y Landeta, J. (2010). El estudio de casos como metodología de investigación científica en dirección y economía de la empresa: Una aplicación a la internacionalización. Investigaciones Europeas de Dirección de la Empresa (IEDEE), 16(31), 3-52.

Yin, R. K. (1989). Case Study Research. Design and Methods (Applied Social Research Methods Series, vol. 5). Sage: Londres.

Zapata, E., Townsend, J., Rowlands, J., Alberti, P. y Mercado, M. (2002). Las mujeres y el poder: contra el patriarcado y la pobreza. Montecillo: Cole 